\title{
Analysis of change characteristics in Chinese mainland surface climate elements during 1961-2010
}

\author{
ZHOU Dan, ZHANG Bo, AN Mei-ling \\ College of Geography and Environmental Science \\ Northwest Normal University \\ Lanzhou, China \\ www.zhoudan.6666@163.com
}

\author{
LUO Jing \\ College of Life and Geographical Science \\ Qinghai Normal University \\ Xining, China \\ Luojing2297741@126.com
}

\begin{abstract}
We drew on data of annual mean temperature, the minimum and maximum temperature, annual extreme minimum and maximum temperature from 468 meteorological stations during 1961 2010 of China, analyzed the variation characteristics of climatic factors in recent fifty years by using the linear regression, Morlet wavelet and Mann-Kendall methods. The results showed the annual mean temperature, the minimum and maximum temperature, annual extreme minimum temperature and annual extreme maximum temperature displayed a significant increasing trend. The significant cycles in the range of 14 16 years' existed in the annual mean temperature, the minimum temperature, the maximum temperature and annual extreme maximum temperature, while the cycles in the range of $25 \sim 26$ years' existed in the annual extreme minimum temperature. Under the confidence level of 0.05, several years of climatic change were found such as in 1996, 1981, 1997 among different series.
\end{abstract}

Index Terms - the ground of mainland China, annual mean temperature, anomaly

\section{INTRODUCTION}

The IPCC in 2007 officially released the fourth assessment report (AR4) officially. Fourth assessment report concluded [1]: in recent 100 years (1906 2005) the average global surface temperature increased by $0.56^{\circ} \mathrm{C} \sim 0.92^{\circ} \mathrm{C}$.

Regional climate change detection and causes identification requirements for as long as possible past climate time series to study. For this purpose, the instrument observation data should have at least 100 years of records. Considering the global climate heating in the late 20th century is one of the most obvious period in the past at least 140 years, and most scholars think nearly 50 years heating is mainly man-made by increased atmospheric concentrations of greenhouse gases [1 2], and choose the ground instrument observation data since 1961 analysis the mainly basic feature of climate change in mainland China in this period still has the very vital significance.
For nearly a century since the $1980 \mathrm{~s}$, the domestic scholars of China instrument observation period of climate change on a lot of research, made a lot progress [3 5]. Wang (1990) first for nearly a century in our country and the global temperature change trend are studied; Ren (2005) on the ground in China from 1951 to 2000 in climate change characteristics were studied; Tang (2005) on China from 1951 to 2002 , on average, maximum and minimum temperature and daily range is studied. These research work suggest that China nearly a century the temperature change and the global or the northern hemisphere is similar, all show the 30 40s and 80s of the 20th century two significant warming period.

For study the nearly 50 years of climate change also to deepen researching. In existing Chinese temperature sequence, for example, the non uniformity problems of data are still prominent, but in the establishment of the national or regional surface average temperature sequence, during the process of most studies haven't to properly handle it; On the other hand, China's surface climate change analysis work most haven't follow strict inspection method, there is no reasonable considering information standardization, spatial interpolation, enlightenment and area weighted average, confined to a few simple statistical calculation, need to be improved in the study.

\section{II . DATA AND METHODS}

Data from China Meteorological Data Sharing Service provided by China's 468 stations from 1961 to 2010 the average data year by year. Annual average temperature of 1961 2010 years' data uniformity inspection and correction, strictly control the quality of data. In at home and abroad on climate data homogeneity testing method and technology, and reform of the basic meteorological observation stations of China, instrument replacement, etc, on the basis of historical evolution, select climate data, such as the Easterling [6] uniformity test and the correction method, the entire base stations in the annual mean temperature series of clear 
breakpoint has carried on the screen, and revised according to the results of the screening. Point in more than 700 weather stations across the country, through strict quality control, short of two years or discontinuous measurement of meteorological site entirely abandon, meet the requirements of meteorological site to 468 .

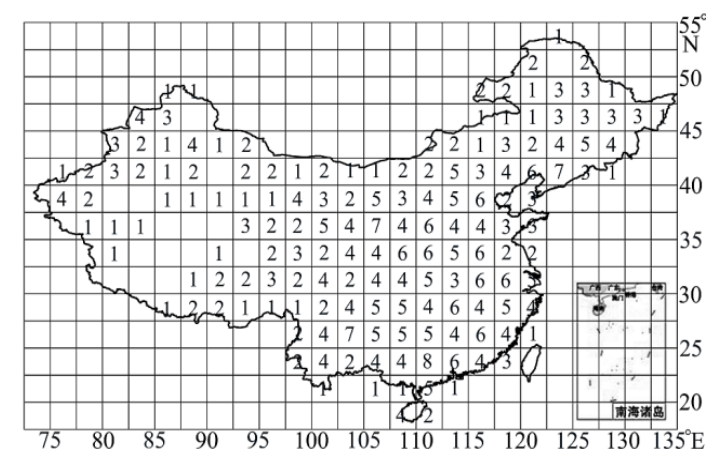

Fig.1. Number of meteorological stations for grids in Chinese

$$
\text { mainland }
$$

When we establish a national average of time series for each elements, we used Jones' [4, 7] area of computing the average climate time series method. First divides the Chinese whole area according to the latitude and longitude grid, the grid size is generally $2.5^{\circ} \times 2.5^{\circ}$ (Fig.1). Then all site data to do arithmetic average in each grid', get the average value of each grid. The application area of the weighted average method to calculate all the grid points, get the average of each factor time series. According to this method, the mainland area was divided into 180 grid' units, the total area is 157.35 units.

Wavelet analysis method in time and frequency domain at the same time has good local property, can be analyzed out the local characteristics of time sequence cycles. Mann -Kendall is a nonparametric statistical test method, it has the advantage of samples don't need to follow certain distribution, also is not affected by the interference of a few outliers, more suitable for the type and order variables, is widely used in climate sequence mutation analysis.

\section{THE INTER-ANNUAL VARIABILITY OF METEOROLOGICAL ELEMENTS}

Ground meteorological elements in mainland of China, the annual average temperature, annual mean minimum and maximum temperature, annual extreme minimum and maximum temperature are significantly upward trend (Fig.2 a, $\mathrm{b}, \mathrm{c}, \mathrm{d}, \mathrm{e})$, the annual rate of $0.027,0.037,0.021,0.053$, $0.016{ }^{\circ} \mathrm{C} / \mathrm{a}$, and the year of the correlation coefficient is 0.827 , $0.906,0.688,0.751,0.479$, respectively both by the confidence level of 0.001 inspection. From 1961 to 2010, mainland of China ground annual average temperature rise very significantly, change rate is $0.027^{\circ} \mathrm{C} / \mathrm{a}$, a rise the average temperature $1.35^{\circ} \mathrm{C}$ in 50 years, warming starts mainly from the mid of 1980s. The annual mean minimum temperature rise of mainland China particularly significant, change rate is $0.037^{\circ} \mathrm{C} / \mathrm{a}$, and between 50 years risen by about $1.85^{\circ} \mathrm{C}$. Mainland of China ground change rate of annual average highest temperature is $0.021^{\circ} \mathrm{C} / \mathrm{a}$, and between 50 years risen by about $1.05^{\circ} \mathrm{C}$. Trend of annual extreme minimum temperature increase is significantly, the change rate is $0.053^{\circ} \mathrm{C} / \mathrm{a}$, and between 50 years risen by about $2.65^{\circ} \mathrm{C}$. Trend of annual extreme maximum temperature increase is significantly, the change rate is $0.016^{\circ} \mathrm{C} / \mathrm{a}$, and between 50 years risen by about $0.8{ }^{\circ} \mathrm{C}$.
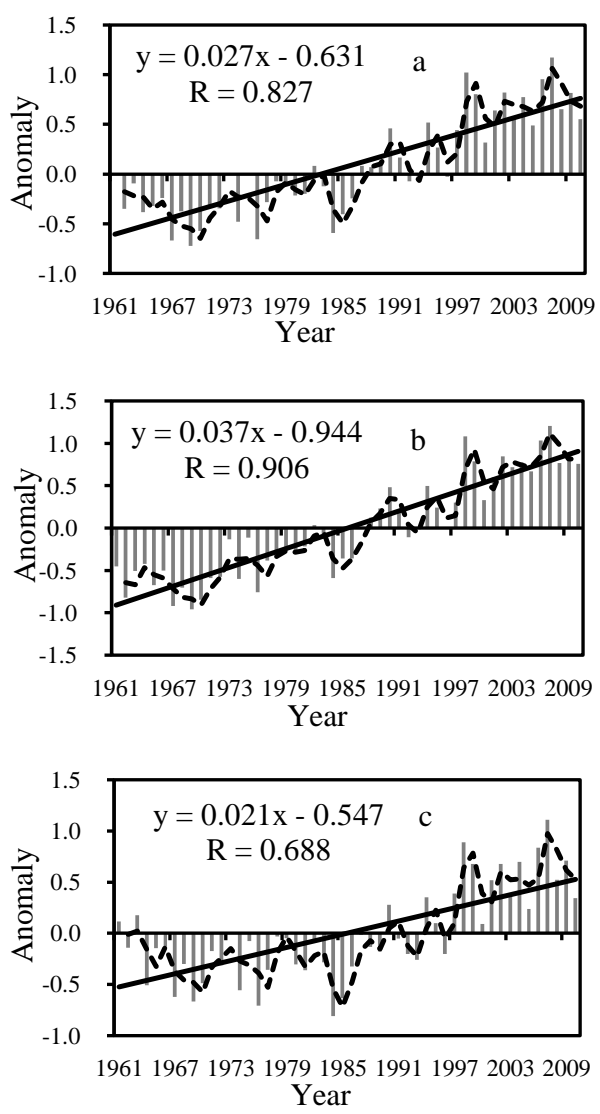

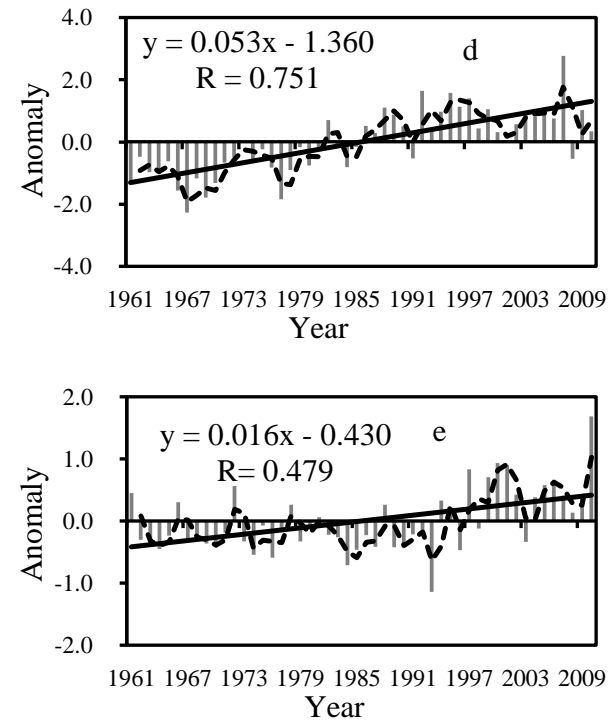

Column in actual inter annual variability; Diagonal lines for many years the trend line; Virtual curve for 3 a moving average

Fig.2. Chinese mainland each climatic elements of annual variation trend

\section{VARIOUS METEOROLOGICAL ELEMENTS IN} CYCLES

Mainland China ground annual average temperature is 4 6, 10 16, 22 26 years' three oscillating cycles (Fig.3a), in 14 and 24 years' left and right oscillation cycles on a strong, about 14 years of oscillation is the main cycle. The annual mean minimum temperature is 10 16, 20 28 years' two period of oscillation (Fig.3b), in 14 and 25 years' oscillation cycles on intense, about 14 years of oscillation is the main cycle. Mainland China ground annual average highest temperature is $5 \sim 7,8 \sim 16,22 \sim 26$ years' three oscillating cycles (Fig.3c), at about 6 years', 14 years', 24 years' oscillation cycles on intense, 14 years cycle of oscillation is the main cycle. Mainland China ground annual extreme lowest temperature is 10 14, 20 28 years' two period of oscillation (Fig.3d), in 12 and 25 years' oscillation cycles on strong, among them 25 years cycle of oscillation is the main cycle. In mainland of China ground extremely highest temperature there is $6 \sim 10,12 \sim 18$ years' two period of oscillation (Fig.3e), around 8 and 16 years' oscillation cycles on intense, about 16 years of oscillation is the main cycle.
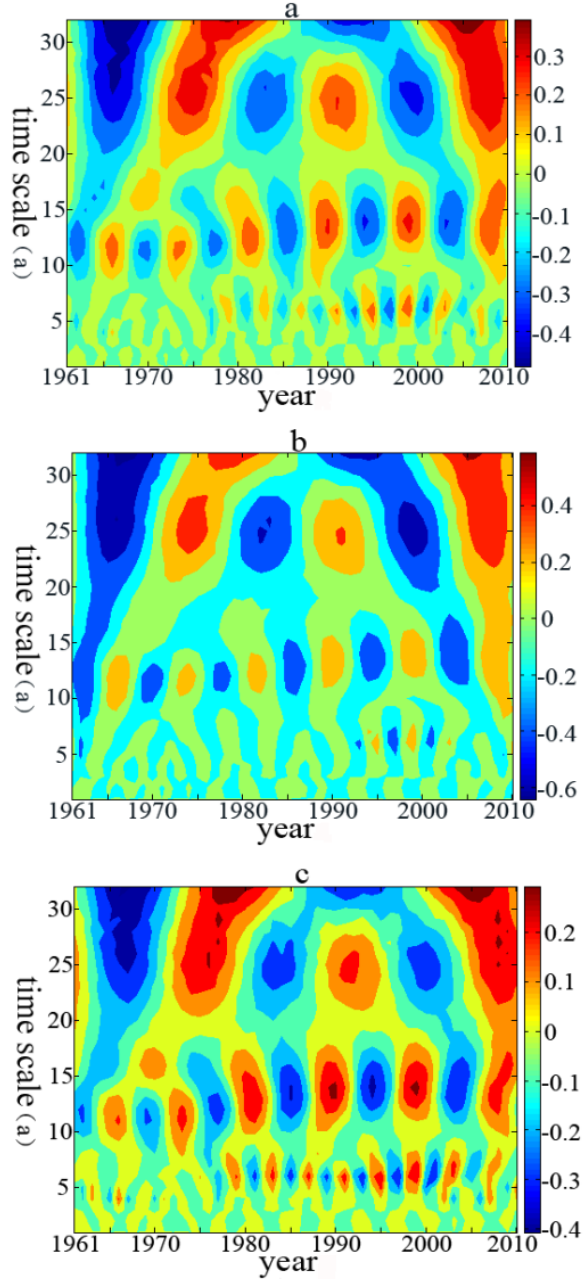

d
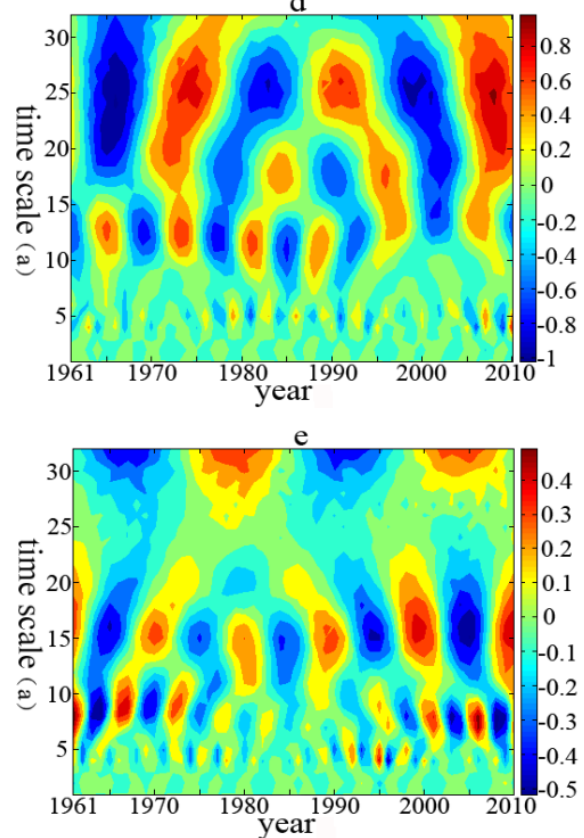

Fig.3. Chinese mainland meteorological elements of time-frequency wavelet transform 


\section{V . THE CLIMATE ELEMENTS IN MUTATION}

Under the confidence level of $0.05 \quad\left(\mathrm{U}_{0.05}= \pm 1.96\right)$, mainland of China annual average temperature, annual mean minimum temperature not mutations (Fig.4 a, b). Highest annual average temperature, annual extreme lowest temperature, annual extreme maximum temperature are mutated, it respectively in 1996, 1981, 1997 mutations (Fig.4 $\mathrm{c}, \mathrm{d}, \mathrm{e})$. Mutations before the average, respectively-0.22, -0.95 , $-0.21^{\circ} \mathrm{C}$, average after mutation were $0.52,0.63,0.54^{\circ} \mathrm{C}$, and the mutation than before after increased $0.74,1.58,0.75{ }^{\circ} \mathrm{C}$, respectively. Average annual highest temperature in the mid of 1990s mutation increases, annual extreme lowest temperature in the early 1980s mutation increased, extreme maximum temperature in the late 1990s mutation increased. Mutations in among them, the extreme maximum temperature mutations time one year later than average temperature the highest temperature mutations can be seen in the extreme maximum temperature change starts with the annual average highest temperature changes.
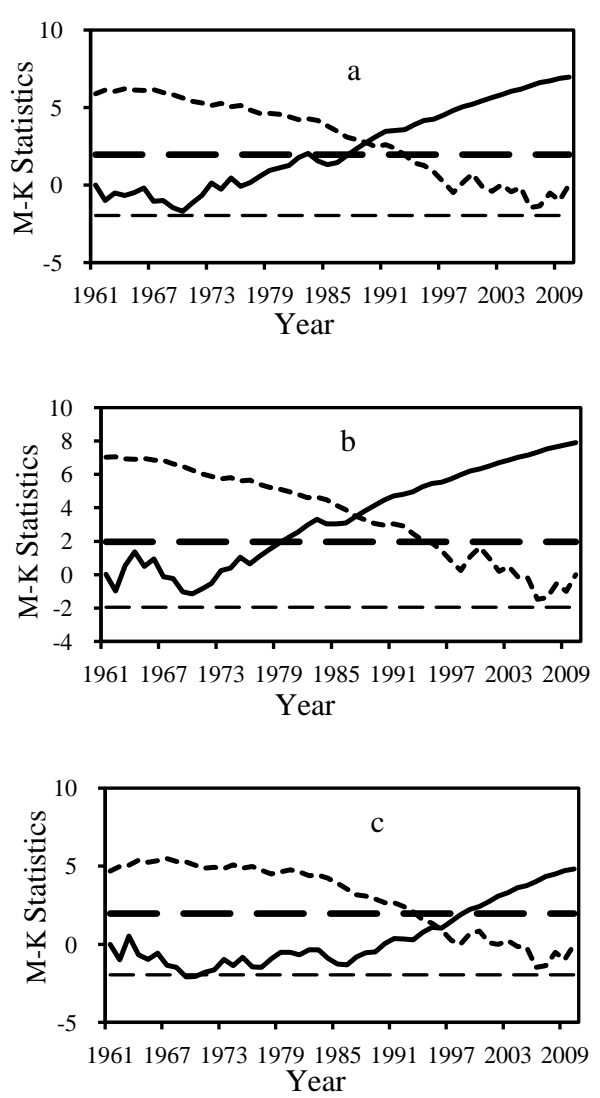
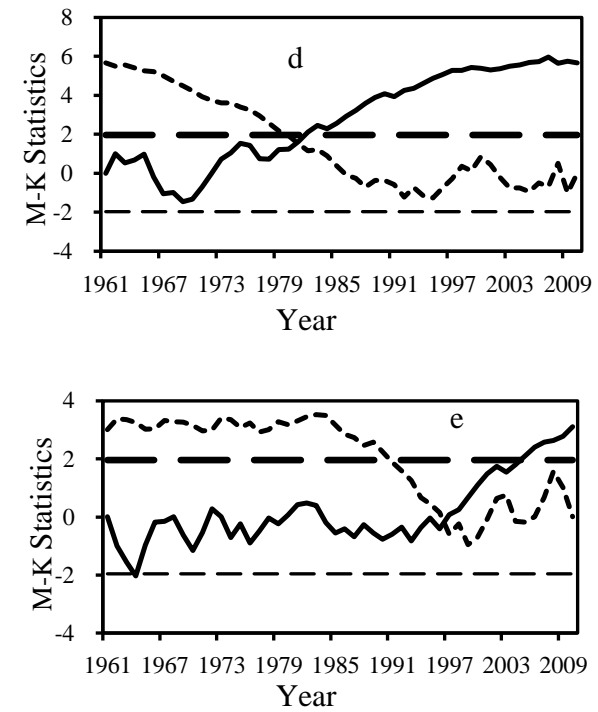

Solid line for UF curve; Imaginary line for UB curve; Short term for the critical value; Fine day for the next critical value

Fig.4. Mutation test of Chinese mainland each climatic elements

\section{CONCLUSION AND DISCUSSION}

1). In the Chinese mainland surface climate elements, the annual average temperature, annual mean minimum and maximum temperature, annual extreme minimum and maximum temperature are in obviously rising trend, between 50 years respectively increased by about 1.35, 1.85, 1.05, 2.65, $0.8^{\circ} \mathrm{C}$. It is tiny differences with Tang (2005) and Wang (2010) the results $[5,8]$. Wang' climate on general situation research of China in 2010, according to nearly 50 years mainland China increased rate of annual average temperature of ground is $0.03^{\circ} \mathrm{C} / \mathrm{a}$; Tang' research on average lowest, highest air temperature in China shows according to a study in mainland China from 1961 to 2002 average annual minimum ground temperature rise rate is $0.033^{\circ} \mathrm{C} / \mathrm{a}$, annual mean maximum temperature rise rate of $0.014^{\circ} \mathrm{C} / \mathrm{a}$.

2 ). The ground of mainland China cycle of climate change is a bit different, but mainly concentrated in 14, 16, 25 or so years'. With annual average temperature, annual mean minimum temperature, annual mean maximum temperature, extreme maximum temperature changes in the primary cycle in about 14 16 years', the annual extreme lowest temperature primary cycle are around 25 years'.

3 ). The ground of mainland China climate elements under the confidence level of $0.05\left(\mathrm{U}_{0.05}= \pm 1.96\right)$, the highest annual average temperature, annual extreme lowest 
temperature, annual extreme maximum temperature, respectively, in 1996, 1981, 1997 mutations increase. Among them the extreme maximum temperature mutations in time than the average highest temperature mutations late about one year, can be seen in extreme maximum temperature changes from the annual average highest temperature changes in the beginning.

\section{ACKNOWLEDGMENT}

The authors wish to thank the China Meteorological Data Sharing Service System for the pre-processing of the data of the meteorological station.

\section{REFERENCES}

[1] Ministry of water resources to tackle climate change research center, "Authoritative report on climate change-the IPCC report”, J. China Water Resources, No.2, 2008, pp. 38-40.

[2] Qin D H, Luo Y, Chen Z L, "The latest progress of the science of climate change - the IPCC fourth assessment comprehensive report analysis", J. Research Progress on Climate Change, Vol.3, No.6, 2007, pp. 311-314.

[3] Wang S W, "Nearly a century of China and the global temperature change trend", J. Journal of Climate, No.2, 1990, pp. 11-15.

[4] Ren G Y, Guo J, Xu M Z, "Nearly 50 years Chinese ground characteristics of climate change", J. Journal of Climate, Vol.63, No.6, 2005, pp. 942-956.

[5] Tang H Y, Zhai P M, Wang Z Y, “1951 2002 years China's average maximum and minimum temperature and daily range changes", J. Climatic and Environmental Research, Vol.10, No.4, 2005, pp. 728-735.

[6] Easterling D R, Peterson T C., "A new method for detecting and adjusting for undocumented discontinuities in climate meteorological time series". Int J Climatol, Vol.15, pp. 369-377.

[7] Jones P D, Hulme M., "Calculating regional climatic time series for temperature and precipitation: the methods and illustrations". Int J Climatol, Vol.16, 1996, pp. 361-377.

[8] Wang Z Y, Zeng H L, Gao G, Cheng Yu, Si Dong, Liu Bo, "2010 Chinese climate survey", J. Journal of Climate, Vol.5, No.4, 2011, pp. 439-445. 